\title{
Discussion on the Social Governance Amid After-School Tutorial Classes and the Quality-Oriented Education
}

\author{
Qiaowen Tang \\ School of Humanities and Social Sciences, North China Electric Power University, Beijing, 102206, China \\ *Corresponding author.Email: aven_tqw@163.com
}

\begin{abstract}
The educational reform based on quality-oriented education is a key aspect of modern system of social governance. Not only are there some opposed competitions and games, but also some mutual promotions and divergences amid the phenomenon that primary and secondary school students participating in after-school tutorial classes and quality-oriented education advocated by educational reform. The multiple subject of education is composed by governments, societies, patriarchs and students, and their standpoints of educational reform are determined by divergences which depend on their value-oriented of educational benefits. By studying and analyzing the data involved 11,886 respondents, the developmental trend between after-school tutorial classes and quality-oriented education was carried out, and strategies and suggestions inducting for systematic modernization of social governance were proposed. On the basis of student-centeredness, a harmony between complementary advantages and improved education quality is formed, and education reform is effectively promoted.
\end{abstract}

Keywords: educational reform, after-school tutorial classes, quality-oriented education, social governance

\section{INTRODUCTION}

At present, it's ranked the first place by Chinese education all over the world. With the ever intense competition in education, it has been conventionalized for primary and secondary school students to attend after-school tutorial classes. The lack of a thorough understanding of qualityoriented education leads to a misunderstanding that there is a conflict between quality-oriented education and afterschool tutoring. Quality-oriented education is mistaken for exam-free, focused on skill development and free from constraints [1]. All these have led to widespread prejudice against the education and teaching of after-school tutoring institutions, which do assume values in multiple aspects whereas. Firstly, after-school tutoring has certain social value. On the one hand, it caters to the demand of students and parents for personalized education. Driven by the talent cultivation concept of "elite education" and the differences in teaching levels in different schools, some parents and students are eager for private education resources, which are satisfied by the after-school tutoring education as a supplement to public welfare and universal education. On the other hand, an increasing number of after-school tutoring institutions are committed to launching products that meet the educational value orientation of comprehensive development, which has greatly alleviated the demand of some students and parents for the second classroom. From the perspective of national educational development, these institutions are beneficial to the development of education. In view of the value orientation consistent with quality education in a way, they are the supplement and promotion of educational resources as social forces. In addition, the economic value of after- school tutoring institutions should by no means be overlooked, as evidenced by their positive and irreplaceable role in promoting employment, enriching educational forms and stimulating the development of educational modernization technologies.

\subsection{Phenomenon of After-school Tutorial Classes Education}

\subsubsection{Cause of formation}

As for the causes of primary and secondary school students' participation in after-school tutoring, and reached the following two conclusions.

\subsubsection{National conditions of educational development in China.}

It is widely acknowledged that there are problems in China's educational resources, such as insufficient accumulation, unbalanced regional development and unreasonable regional differences in enrolment opportunities. There is still a gap between the demand and supply of high-quality educational resources as public service products. In literature [2-3], the inequality of educational resources is explored from the aspects of local government's public decision-making on education and local financial capacity. In literature [4], the author suggested that the people's education leads to differences with the three economic regions: the eastern developing 
region, the western exploiting region and the central springing region. Moreover, given that the college entrance examination is still taken as the primary talent selection mechanism in China, the assessment of academic performance dominates, implying the inevitability of primary and secondary school students taking on various challenges and pressures for further study. This has constituted the source of their value orientation for attending after-school tutorial classes. The multi-interest game involving schools, parents and students, such as the grading of schools by the education authorities, the selective admission of some key middle schools put in their admission notices, etc., has triggered the emergence and growth of after-school tutoring.

\subsubsection{Stimulated by economic interests.}

The pursuit of economic interests has contributed to the prosperity of the after-school tutoring market. The fees charged by tutoring agencies far exceed those of compulsory education, thereby propelling them to exaggerate the role of attending tutorial classes and increase investment in commercial publicity. A number of factors, including advertising effect, herd mentality, selfinterest expectation and passive guidance, have objectively stimulated and induced primary and secondary school students to attend after-school tutorial classes.

\subsubsection{Trend analysis of the development}

In this study, a total of 11,886 primary and secondary school students of all grades and their parents involved the survey and formed a sample as shown in Table 1.

Table 1 Composition of respondents

\begin{tabular}{|c|c|c|c|c|c|}
\hline \multirow{2}{*}{ Grade } & \multicolumn{2}{|c|}{ Primary School } & \multirow{2}{*}{ Junior middle school } & Senior middle school & Total \\
\cline { 2 - 3 } & $1-3$ & $4-6$ & & 4563 & 11886 \\
\hline Number of people & 1773 & 1484 & 4066 & 456 \\
\hline
\end{tabular}

According to the statistics, about $92.78 \%$ of the total number of students have attended or are attending afterschool tutorial classes, among which $97.36 \%$ are junior two, junior three, senior two and senior three and $89.87 \%$ are junior one and senior one. Through data analysis, students' participation in after-school tutoring demonstrates four characteristics. First of all, students attending after-school tutorial classes are of lowering ages. Secondly, various courses are offer in tutorial classes. It indicates that the participation of students of all grades including the primary ones in after-school tutoring is extending from some backward courses to all courses. The third is the longer cycle of after-school tutorial classes. The after-school tutorial classes are extending to the whole academic stage from the previous cycle of nearly one year before admission. Finally, the courses provided by tutorial classes are transformed from music, physical education, art and dance of lower grades to mathematics, physics, chemistry, English and other advanced examination subjects of higher grades. As one of the subjects in the high school entrance examination, physical education has been attached great importance.

\subsubsection{Existing deficiency}

\subsubsection{Deficiency with the tutorial classes agencies.}

The shortcomings of tutoring institutions might be concluded as: (1) Inadequate faculty. Most tutoring institutions suffer from a shortage of teachers and poor stability, resulting in a low proportion of professional talents; (2) Limited teaching conditions. The majority of tutoring institutions are short of hardware teaching resources including various experimental equipment, which lead to the failure of chemistry, physics and biology experiments to achieve desired effect; (3)Lagging teaching research. Tutoring institutions rarely carry out teaching research, as embodied by the lack of systematic research on educational theory as well as teaching practice, methods, links and objects; (4) The educational concept behind the times. The lack of exploration and implementation of advanced educational concepts is inevitable in view of the profit-oriented purpose of afterschool tutoring institutions.

\subsubsection{Deficiency with students participated to after-school tutorial classes.}

Students' participation in after-school tutorial classes has disadvantages as well. (1)First of all, most of the learning methods promoted by tutorial classes fail to conform to the laws of education and teaching, thus bound to hinder students from developing favourable learning habits. Aiming at improving students' academic performance in a short time, tutorial classes violates the teaching and learning laws of deduction, perception, understanding, consolidation and application. Moreover, due to the lack of collectivism and teamwork education, students have little 
sense of belonging to these institutions; (2)It brings more academic burden to students. It takes up the rest and sleep time of primary and secondary school students, deprives them of the opportunity to carry out scientific exploration that are genuinely appealing to them [5]; (3)By putting on greater economical load to the family, it exerts a negative impact on family life. Compared with compulsory education, the high charge of after-school tutorial classes is a heavy burden for most families, which aggravates the inequality of students' access to educational resources in families with income differences; (4) security issues. Primary and secondary school students are confronted with hidden dangers in terms of personal, property, traffic safety and mental health during their participation in afterschool tutorial classes.

\section{QUALITY-ORIENTED EDUCATION}

\subsection{Connotations of Quality-oriented Education}

In education, exam-orientation should never be the only pursuit, while the combination of knowledge acquisition and physical and mental health, social demands and individual needs should be tried to achieve through the integration of quality-oriented education and examoriented education [6]. With the development of economy and the improvement of people's living standards, the value orientation of China's education policy is increasingly diversified, presenting the characteristics of the transition from state-centred to people-oriented, the return from instrumental value to ontological value, and the diversion from single value to value integration. Based on this, the understanding of quality-oriented education might as well be analyzed from two aspects. The first is the idea of "people-oriented orientation", which focuses on the development of people and takes their change and growth as the goal of education. In this way, the value orientation of quality-oriented education, which centres on the healthy growth and development of students, coincides with the view of Confucius and Mencius that "education is for the enrichment of one's own heart rather than the adaptation to the outside world". The second is the idea of "social needs". According to the literature [7], qualityoriented education in China is expected to take the whole picture into account to adapt to China's and global economic and social development. Focusing on whether human development meets social needs and advocates the combination of human practice and social needs, it argues that human practice should cater for social needs and achieve career achievements by means of livelihood. The satisfaction degree of "social needs" other than humanoriented development is taken as the evaluation index. Quality-oriented education ought to achieve the combination of the two.

\subsection{Approaches of Quality-oriented Education}

In view of the obstacles to quality-oriented education caused by the overloaded learning burden facing primary and secondary school students, it is required to liberate students from the heavy academic load and break the entrance-oriented competition. While consuming students' interest in learning, such burden is weakening their motivation to learn. The construction of efficient classroom teaching has been proved to be quite effective in reducing the workload of primary and middle school students. In light of the characteristics of physical and mental development of primary and secondary school students, compared with the traditional passive mode of indoctrination and coercion, the education of them is suggested to turn to the active mode of guidance and inquiry [8]. In this way, the students' enthusiasm for learning and thirst for knowledge will be stimulated while forming the study habit. Efficient classroom shall assist students in achieving the set learning goals by making good use of time, mastering key knowledge, and motivating their curiosity. Through the teaching process including problem guidance, feeling and experience, abstraction and generalization, acquisition and application of new knowledge, consolidation and improvement, expansion and reflection, etc., efficient classroom shall be surely conducive to arouse learners' enthusiasm and confidence in learning and creation [9].

\section{STRATEGIES AND SUGGESTIONS}

Considering that educational reform close tie to the whole society, both its scientificity and rationality are crucial prerequisites for promoting the modernization of social governance system. Education reform will not happen overnight. While avoiding conformity or blind imitation, we should take into account rational education, inclusive reflection and transcendental guidance [10]. The quality of education at each stage is marked by social and individual needs at that time. Directly or indirectly, the competition between social and individual needs and reality exerts an influence on educational activities and promotes the continuous change and renewal of educational quality concepts. Therefore, along with the improvement of education level comes the urgent desire for the modernization of social governance system. The relationship between social governance and educational reform, as well as the multiple subjects of education, is as shown in Figure 1. 


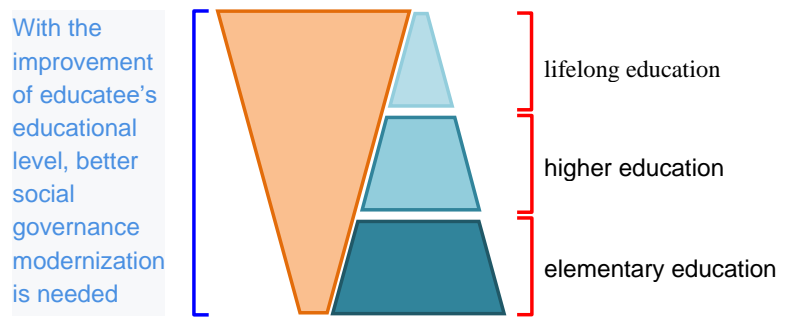

Figure 1 Requirement between social governance and educatee's educational level

\subsection{Methods from Government Layer}

As the government, the corresponding suggestions are as follows. Above all, it is required to comprehensively improve the capacity of law-based governance, so as to upgrade the government's guidance and supervision system for education. By continuing to promote education reform in accordance with the law, "providing education to the satisfaction of the people" shall always be given top priority. From the aspects of legislation, law enforcement, judicature and law abiding, the advancement of education reform and the protection of the rights and interests of all parties shall be ensured, with a view to building a systematic, scientific, normative, adaptive and effective legal system of education reform.

Then, the fairness of compulsory education should be promoted by abolishing the authority of educational authorities to grade schools. The enrolment system of basic education examination should be improved by combining the school district system of primary school, middle school and high school with other enrolment methods, and introducing methods such as classified examinations, optional subjects, comprehensive evaluation, two-way selection and multiple enrolments. The reform of the college entrance examination system should be accelerated and the construction of a diversified college entrance examination evaluation and enrolment system should be accelerated [11]. Through the overall allocation of academic, applied and quality subjects in the college entrance examination, the proportion of quality-oriented education should be increased, so as to achieve the balance of educational objectives and examination difficulty, as well as the enrolment ratio of schools in different regions, ease the grading of students among schools and further realize the fairness of admission. With regard to the teachers, strict restraints should be placed on teachers in law and system while improving their salary and formulating occupational ethics. The behaviour of school teachers in organizing or attending after-school tutorial classes should be ensured reasonable and legislated, which should resort to the law to regulate their after-school educational activities. It is recommended to apply strict regulations to all after-school tutoring institutions in society, including explicit guidance and supervision in terms of qualification, faculty, school buildings and management.

\subsection{Methods from Social Layer}

Thirdly, fundamentally change educatees' interpretation of education through the transformation of educational concept. As a result of some improper talent mechanism, the social education concept has been directed to the unfavourable aspects and spread to the whole education system, as evidenced by parents' and students' attachment to famous universities. In such context, the demand for private education continues to grow and the phenomenon of comparison aggravates which promotes the development of after-school tutoring and strengthens the value orientation of exam-oriented education. Through the systematic promotion of education, the cultivation of key abilities to support students' lifelong development and adapt to the requirements of the times should be attached concern, while a new teaching relationship based on students' development should be established. The talent evaluation mechanism should be reformed and the utilitarian thought of "score only" should be reversed. Finally, the hierarchy of schools should be gradually weakened to achieve the whole society's recognition of the educational ideal, mission, purpose, ideal, goal, requirement and principle of "people-oriented", thus ensuring the favourable results of quality-oriented education reform and the promotion of educational equity.

\subsection{Methods from Familial Layer}

Given the dominant position of students in education, both parents and students should be committed to the development of students' moral conduct, cultivation of positive mentality, improvement of academic performance, enhancement of health status and distillation of artistic quality [12]. We have to admit that education without tests (grades) shall not justify itself, while education for tests alone is necessarily imperfect. The utilitarian goal of education leads to the alienation of primary and secondary education and the resulting pursuit of private education promotes the development of for-profit tutoring institutions. A vicious circle eventually formed, that is, parents and students excessively rely on after-school tutoring education. Aristotle's belief that "education ought to be based on three principles, namely, the mean, possibility and appropriateness" is recognized as the best speculation on the value orientation of education. "The mean" reminds us to avoid excessive or insufficient in education, "possibility" means that students are expected of all possibilities in their growth and development, and "appropriateness" implies that the teaching approaches should conform to the law of education and be suitable for the object of it. Adhering to the concept of teaching students in accordance with their aptitude, only by following the law of human growth and in line with the current physical and mental status of students of different ages can the realization of the value of education be ensured. 
[5] H. P. Xue, Y. Zhang. An analysis of the level and

\section{CONCLUSION}

Rather than advocating pure "score only" or "quality only", in the educational reform, both quality education and afterschool tutoring should be devoted to effectively improving students' mastery and understanding of knowledge. Students' academic performance and comprehensive quality should be given equal attention to ensure parallel development. Being "learner-centred", it is expected to promote the development of quality-oriented education by carrying out legal governance through the cooperation of the government, society, parents and students, constantly improving the guidance and supervision system, changing the concept of social education and following the law of education while realizing the individualized development of people.

\section{ACKNOWLEDGMENT}

This work was supported by Innovation and entrepreneurship training program for university students of North China Electric Power University (201902253). Meanwhile, I will be very felicity to appreciate Lu Haiyan and Tang Minan for their help.

\section{REFERENCES}

[1] J.Y. Su. Quality education: epistemological misunderstandings and its rectification. Journal of Beijing Normal University (Social Sciences). (06) 2008:29-35. DOI: https://doi.org/10.3969/j.issn.10020209.2008.06.004

[2] N. N. Liu. Study on the regional differences in the entrance opportunities of high-quality higher education in China. Chongqing Higher Education Research. 8(01) 2020: 37-46. DOI: https://doi.org/10.15998/j.cnki.issn 1673- 8012.2020.01.004

[3] M. Lu, J. Fang, Z.X. Du et al. Report on the development of preschool education in western China. Journal of east China normal University (Educational Sciences Edition). 38(01) 2020: 97-126. DOI: https://doi.org/10.16382/j.cnki.1000-5560.2020.01.009

[4] L.L. Chen. Estimation about education disparity during the Chinese reform. Advances in Information Sciences and Service Sciences. 3(9) 2011: 368-375. DOI: https://doi.org/10.4156/AISS.vol3.issue9.47 difference of academic burden of junior middle school students in China: Empirical research based on CEPS2015 Data. Journal of Capital Normal University (Social Sciences Edition). (05) 2019: 147-166. DOI: https://doi.org/10.3969/j.issn.1004-9142.2019.05.018

[6] Y. P. Li. The modernity construction of Confucius' thought of teaching students in accordance with their aptitude. Journal of Hunan University of Science \& Technology (Social Science Edition). 22(06) 2019: 155161. DOI: https://doi.org/10.13582/j.cnki.1672-7835. 2019. 06.022

[7] S. Vilairat. Gains and Losses in the development of comprehensive education in China. Fudan Education Forum. 17(06) 2019: 12-17. DOI: https://doi.org/ 10.13397/j.cnki.fef.2019.06.004

[8] X. J. Yuan, Y. S. Song, Z. M. Gong, S. N. Ma, X. L. Kong. Reform the teaching mode of curriculum and improve the ability of independent learning. Journal of Southeast University (Philosophy and Social Science). 14(S2) 2012: 83-85. DOI: 10.13916/j.cnki.issn1671511x.2012.s2.068

[9] M. Antona, A Leonidis, G Margetis, M. Korozi, S. Ntoa, C Stephanidis. A student-centric intelligent classroom. Lecture Notes in Computer Science. (7040) 2011: 248-252. DOI: http://orcid.org/0000-0002-91016301

[10] J. WANG, J. L. LIU. Query and transcend: the value implication of rational education criticism in educational reform. Journal of Educational Science of Hunan Normal University.14(06) 2015: 30-33. DOI: https://doi.org/1671-6124(2015)06-0030-04

[11] Z.Z. Ren, X. Zhao, A. Chen. Deepening the content reform of college entrance examination and promoting the development of quality education: the key issues and solutions in the reform. China Higher Education Research. (01) (2019) 38-42. DOI: https://doi.org/10.16298/j.cnki.1004-3667.2019.01.08

[12] J.Z. Zhou. Quality education in the new era with new conceptions and requirements. Journal of Hebei Normal University (Educational Science Edition). 20(04) 2018: 41-44. DOI: https://doi.org/10.13763/j. cnki. jhebnu. ese.2018.04.004 